\title{
Twin pregnancy-maternal and fetal complications its association with mode of delivery: a study in a tertiary center
}

\author{
Jupirika E. Pyrbot*, Manika Agarwal
}

Department of Obstetrics and Gynaecology, North Eastern Indira Gandhi Regional Institute of Medical and Health Sciences, Shillong, Meghalaya, India

Received: 07 September 2017

Accepted: 29 September 2017

*Correspondence:

Dr. Jupirika E. Pyrbot,

E-mail: jupirika@gmail.com

Copyright: () the author(s), publisher and licensee Medip Academy. This is an open-access article distributed under the terms of the Creative Commons Attribution Non-Commercial License, which permits unrestricted non-commercial use, distribution, and reproduction in any medium, provided the original work is properly cited.

\section{ABSTRACT}

Background: Twin pregnancies are associated with many complications. Hence the mode of delivery and its effect on the maternal and foetal outcome is important.

Methods: A retrospective study of twin pregnancies carried out from April 2015 to March 2017 in a tertiary hospital in north east, India. The maternal, foetal outcome and the mode of delivery data collected and analysed.

Results: A total of 50 twin pregnancies studied. The prevalence of twin was 20/1000 deliveries. Most common age group was 20-29 years with a mean age of 28+5.7 years. A total of $24(48 \%)$ had vaginal delivery and $26(52 \%)$ had LSCS, $2(4 \%)$ had the first twin as vaginal delivery and second twin LSCS. A statistical significance was seen in the mode of delivery of twin pregnancies conceived after ovulation induction, $(\mathrm{p}<0.05)$. The most common indication for LSCS was foetal malpresentation (14.58\%) followed by foetal distress $(12.5 \%)$ and elective LSCS $(10.42 \%)$ on patient's request. The most common complication was anaemia $(28.08 \%)$ and PIH (27.08\%). In the neonate prematurity was the most common morbidity. There was no association between the mode of delivery and the foetal outcome in the form of Apgar at 5 minutes, NICU admission and perinatal mortality.

Conclusions: There is a rise of caesarean delivery in twin pregnancies, maternal request becoming one of the causes. Regular antenatal check-ups of pregnant women with counselling regarding the mode of delivery should be carried out.

Keywords: Foetal outcome, LSCS, Maternal, Twin

\section{INTRODUCTION}

The incidence of twin pregnancy has shown to increase over the decade due delayed marriage leading to high incidence of subfertility. Thus, there is an increase use of ovulation induction and the need for IVF. With the increased number of patients undergoing IVF there has been an increased incidence of multiple pregnancies. ${ }^{1,2}$ Twin pregnancy is known to have more obstetrical and neonatal complications as compared to singleton pregnancy. The obstetric complications of multifetal pregnancy include preterm labour, preterm premature rupture of membranes, anaemia, pregnancy-induced hypertension, postpartum haemorrhage, etc. ${ }^{3,4}$ The study of twin or multiple births is important because of the elevated health risks for both mothers and babies, and accompanying greater health care cost. ${ }^{5}$ Perinatal mortality and morbidity in twin pregnancy is five-seven times higher compared to singleton pregnancy. ${ }^{6}$

Prematurity, low birth weight (LBW), birth asphyxia, birth trauma, intrauterine foetal death and congenital malformations are the important factors to explain the reasons of high perinatal mortality. For twin pregnancies, in most countries the average caesarean section (LSCS) rate is about $50 \% .^{7,8}$ 
A previous report of US, twin births demonstrated a relatively high caesarean rate for twin gestation, which rose modestly from $50 \%$ to $56 \% .^{9}$ The optimal mode of delivery in twin pregnancy is still debatable, with most obstetrician preferring vaginal delivery in vertex-vertex presentation. ${ }^{10,11}$ There is a definite rise of caesarean section rate in twin pregnancy with a higher caesarean section rate in those conceived by ART as compared to those conceived spontaneously. ${ }^{12}$

There is also a definite rise in rates of elective caesarean delivery for twins' in spite of a lack of substantial evidence. Maternal apprehension especially in those who have conceived by ART is one major contributing factor leading to high rate of elective caesarean following patient's request. Hence, it is important to identify the various factors which influence the decision regarding the mode of delivery of twins, in order to address this increasing rate of caesarean section.

Various studies have been carried out in relation to twin pregnancy and its outcome. In this study our aim is to study the outcome of twin pregnancy with its relation to the mode of delivery and its trend in a tertiary centre in the North-East part of India.

\section{METHODS}

It is a retrospective study in which all twin pregnancies $>28$ weeks period of gestation admitted in the Department of Obstetrics and Gynecology in NEIGRIHMS hospital have been studied from the period April 2015 to March 2017. Their data have been collected from birth registry and each case record has been studied. Twin pregnancies <28 weeks have been excluded. Both booked cases as well as referred cases have been taken into consideration. The maternal demographics: age, parity, period of gestation, mode of conception, antenatal checkups have been recorded. Maternal complications in the antenatal period, mode of delivery and the postpartum complications have been studied. The indications for LSCS were recorded and those done on maternal request have also been noted. The neonatal outcome in the form of birth weight, Apgar score, maturity and NICU admission has been recorded for both first twin and the second twin.

\section{Statistical analysis}

The data was analysed using the SSPS software for windows. Data analysis described in the form of percentage and means. $\mathrm{P}$ value $\leq 0.05$ was taken as statistically significant.

\section{RESULTS}

In the study a total of 50 twin pregnancies and their outcome have been studied. During this period a total of 2431 deliveries took place giving twinning rate of 20 per 1000 deliveries.

Most women 24 (48\%) admitted were in the age group $20-29$, with the mean age group $28 \pm 5.7$ years. The highest age was 41 years. A total of $26(52 \%)$ women had undergone LSCS and 24 (48\%) had vaginal delivery and $2(4 \%)$ had a vaginal delivery of the first twin followed by LSCS of the second twin. These two cases have been excluded from the statistical data analysis. Among those who have undergone LSCS $10.42 \%$ were done on maternal request. As shown in Table 1, there were 40 $(83.33 \%)$ women $<35$ years of which 19 (47.5\%) had a vaginal delivery.

Table 1: Maternal demographics and the mode of delivery.

\begin{tabular}{|c|c|c|c|c|c|}
\hline \multicolumn{2}{|c|}{ Maternal demographics } & Total & Vaginal & LSCS & P-value \\
\hline \multirow{2}{*}{ Age } & $<35$ years & $40(83.33 \%)$ & $19(47.5 \%)$ & $21(52.5 \%)$ & \multirow[t]{2}{*}{$\mathrm{P}=0.604$} \\
\hline & $\geq 35$ & $8(16.67 \%)$ & $3(37.5 \%)$ & $5(62.5 \%)$ & \\
\hline \multirow{2}{*}{ Gravida } & Primigravida & $14(29.1 \%)$ & $7(50 \%)$ & $7(50 \%)$ & \multirow[t]{2}{*}{$\mathrm{P}=0.710$} \\
\hline & Multigravida & $34(70.83 \%)$ & $15(44.12 \%)$ & $19(55.88 \%)$ & \\
\hline \multirow{2}{*}{$\begin{array}{l}\text { Antenatal } \\
\text { check-up }\end{array}$} & Booked & $22(45.3 \%)$ & $7(31.81 \%)$ & $15(68.18 \%)$ & \multirow[t]{2}{*}{$\mathrm{P}=0.073$} \\
\hline & Unbooked & $26(54.1 \%)$ & $15(57.69 \%)$ & $11(42.31 \%)$ & \\
\hline \multirow{2}{*}{$\begin{array}{l}\text { Mode of } \\
\text { conception }\end{array}$} & Ovulation induction & $12(25 \%)$ & $1(8.3 \%)$ & $11(91.67 \%)$ & \multirow{2}{*}{$\mathrm{P}=0.002$} \\
\hline & $\begin{array}{l}\text { Spontaneous } \\
\text { conception }\end{array}$ & $36(75 \%)$ & $21(58.33 \%)$ & $15(41.67 \%)$ & \\
\hline
\end{tabular}

In women $>35$ years $3(37.5 \%)$ had vaginal delivery and $5(62.5 \%)$ had LSCS. Most of the women were multigravida $34(70.83 \%)$ with primi gravida contributing to $14(29.1 \%)$ of the study group. Of the primi gravida 7 (50\%) delivered vaginally and $7(50 \%)$ delivered LSCS. Among the multigravida $15(44.12 \%)$ delivered vaginally and $19(55.88 \%)$ via LSCS. 22 (45.3\%) women were booked patients having a minimum of three antenatal check-ups in our institute and $26(54.1 \%)$ were unbooked. Of the booked women $7(31.81 \%)$ had vaginal delivery and $15(68.18 \%)$ had LSCS, $\mathrm{p}=0.07$. Most of the women conceived spontaneously $36 \quad(75 \%)$ and $12 \quad(25 \%)$ conceived following ovulation induction including IVF. Among the women conceived following OI $1(8.3 \%)$ 
delivered vaginally and the rest $11(91.67 \%)$ had a LSCS $(\mathrm{p}=0.0026)$.

Table 2 shows the various complications associated with twin pregnancy. Some women had multiple complications. It is seen that the most common complication was anaemia $13(27.08 \%)$ and PIH 13 $(27.08 \%)$. Other complications were Preterm premature rupture of membrane 5 (10.42\%), antepartum haemorrhage 2 (4.17\%), hypothyroidism 4 (8.33\%). In the postpartum complications $10(20.83 \%)$ had postpartum haemorrhage and $3(6.25 \%)$ had puerperal sepsis. Among the women who had anaemia 8 (61.54\%) delivered vaginally and $5(38.46 \%)$ via LSCS, $(\mathrm{p}=0.183)$. Among those with PIH $6(46.15 \%)$ had a vaginal delivery and $7(53.85 \%)$ via $\operatorname{LSCS}(\mathrm{p}=0.978)$.

Table 2: Maternal complications and mode of delivery.

\begin{tabular}{|c|c|c|c|c|c|}
\hline \multicolumn{2}{|c|}{ Maternal complications } & Total & Vaginal & LSCS & P-value \\
\hline \multirow{2}{*}{ PPROM } & Yes & $5(10.42 \%)$ & $2(40 \%)$ & $3(60 \%)$ & \multirow[t]{2}{*}{$\mathrm{P}=0.78$} \\
\hline & No & $43(89.58 \%)$ & $20(46.51 \%)$ & $23(53.49 \%)$ & \\
\hline \multirow{2}{*}{$\mathrm{PIH}$} & Yes & $13(27.08 \%)$ & $6(46.15 \%)$ & $7(53.85 \%)$ & \multirow[t]{2}{*}{$\mathrm{P}=0.978$} \\
\hline & No & $35(72.92 \%)$ & $16(45.71 \%)$ & $19(54.28 \%)$ & \\
\hline \multirow{2}{*}{ Anaemia } & Yes & $13(27.08 \%)$ & $8(61.54 \%)$ & $5(38.46 \%)$ & \multirow[t]{2}{*}{$\mathrm{P}=0.183$} \\
\hline & No & $35(72.92 \%$ & $14(40 \%)$ & $21(60 \%)$ & \\
\hline \multirow{2}{*}{$\mathrm{APH}$} & Yes & $2(4.17 \%)$ & $1(50 \%)$ & $1(50 \%)$ & \multirow{2}{*}{$\mathrm{P}=1.07$} \\
\hline & No & $46(95.83 \%)$ & $21(45.65 \%)$ & $25(54.35 \%)$ & \\
\hline \multirow{2}{*}{ Hypothyroidism } & Yes & $4(8.33 \%)$ & $1(25 \%)$ & $3(75 \%)$ & \multirow[t]{2}{*}{$\mathrm{P}=0.38$} \\
\hline & No & $44(91.67 \%)$ & $21(47.73 \%)$ & $23(52.27 \%)$ & \\
\hline \multirow{2}{*}{$\mathrm{PPH}$} & Yes & $10(20.83 \%)$ & $6(60 \%)$ & $4(40 \%)$ & \multirow[t]{2}{*}{$\mathrm{P}=0.312$} \\
\hline & No & $38(79.17 \%)$ & $16(42.11 \%)$ & $22(57.89 \%)$ & \\
\hline \multirow{2}{*}{ Sepsis } & Yes & $3(6.25 \%)$ & $2(66.67 \%)$ & $1(33.33 \%)$ & \multirow{2}{*}{$P=0.454$} \\
\hline & No & $45(93.75 \%)$ & $20(44.44 \%)$ & $25(55.55 \%)$ & \\
\hline
\end{tabular}

PPROM-preterm premature rupture of membranes; PIH-pregnancy induced hypertension; PPH-postpartum haemorrhage; APH-ante partum haemorrhage

Table 3: Indications for LSCS.

\begin{tabular}{|lll|}
\hline Indication for LSCS & Total & Percentage \\
\hline Foetal distress & 6 & 12.5 \\
\hline Malpresentation & 7 & 14.58 \\
\hline Previous LSCS & 4 & 8.3 \\
\hline PIH & 3 & 6.25 \\
\hline Antepartum haemorrhage & 1 & 2.08 \\
\hline Elective LSCS(maternal request) & 5 & 10.42 \\
\hline
\end{tabular}

$5(10.42 \%)$ had PPROM of which $2(40 \%)$ delivered vaginally and $3(60 \%)$ delivered by LSCS. The women who had PPH $6(60 \%)$ was in women who delivered vaginally and $4(40 \%)$ was seen in LSCS patients. Peuperal sepsis was seen in $2(66.67 \%)$ of women delivered vaginally and $1(33.33 \%)$ in women undergoing LSCS; p-value (0.45).

The most common indication for LSCS was malpresentation 7 (14.58\%) followed by foetal distress 6 (12.5\%). Other indications were previous LSCS 4 (8.3\%), PIH 3 (6.25\%), antepartum haemorrhage 1 (2.08\%) and elective LSCS $5(10.42 \%)$ done on patient's request as shown in Table 3 . There was no maternal mortality. One patient was transferred to ICU in postpartum period and 3 $(6.25 \%)$ received blood transfusion.

Table 4: Perinatal outcome and mode of delivery.

\begin{tabular}{|c|c|c|c|c|c|c|}
\hline \multicolumn{3}{|c|}{ Perinatal outcome } & Total & VAG & LSCS & P-value \\
\hline \multirow{2}{*}{\multicolumn{2}{|c|}{ Prematurity }} & Yes & $28(58.33 \%)$ & $11(39.29 \%)$ & $17(60.71 \%)$ & \multirow{2}{*}{$\mathrm{P}=0.28$} \\
\hline & & No & $20(41.67 \%)$ & $11(55 \%)$ & $9(45 \%)$ & \\
\hline \multirow{4}{*}{ Apgar score } & \multirow{2}{*}{ Twin 1} & $<7$ & $7(14.58 \%)$ & $5(71.43 \%)$ & $2(28.57 \%)$ & \multirow{2}{*}{$\mathrm{P}=0.14$} \\
\hline & & $>7$ & $41(85.42 \%)$ & $17(41.46 \%)$ & $24(58.54 \%)$ & \\
\hline & \multirow{2}{*}{ Twin 2} & $<7$ & $16(33.33 \%)$ & $9(56.25 \%)$ & $7(43.75 \%)$ & \multirow{2}{*}{$\mathrm{P}=0.31$} \\
\hline & & $>7$ & $32(66.67 \%)$ & $13(40.63 \%)$ & $19(59.37 \%)$ & \\
\hline \multirow{2}{*}{\multicolumn{2}{|c|}{ NICU admission }} & Yes & $35(36.46 \%)$ & $14(40 \%)$ & $21(60 \%)$ & \multirow{2}{*}{$\mathrm{P}=0.55$} \\
\hline & & No & $54(56.25 \%)$ & $25(46.3 \%)$ & $29(53.7 \%)$ & \\
\hline \multirow{2}{*}{\multicolumn{2}{|c|}{ Perinatal mortality }} & Yes & $7(7.29 \%)$ & $5(71.43 \%)$ & $2(28.57 \%)$ & \multirow{2}{*}{$\mathrm{P}=0.158$} \\
\hline & & No & $89(92.7 \%)$ & $39(43.82 \%)$ & $52(58.43 \%)$ & \\
\hline
\end{tabular}


In Table 4 , it is seen that $28(58.33 \%)$ of the women had preterm labour, of which $11(39.29 \%)$ had vaginal delivery and $17(60.71 \%)$ had LSCS, $\mathrm{P}=0.28$ with no statistical significance. A total of 96 babies were studied (excluding the two cases). In the first twin Apgar score of $<7$ at 5 minutes was seen in $7(14.58 \%$ ) babies of which 5 $(71.43 \%)$ were delivered vaginally and $2(28.57 \%)$ via LSCS, $\mathrm{P}=0.28$. In second twin $16(33.33 \%)$ had an APGAR $<7$ at 5 minutes of which $9(56.25 \%)$ were delivered vaginally and $7(43.75 \%)$ via $\operatorname{LSCS}, \mathrm{P}=0.14$ Of the total babies' perinatal morbidity was seen in 35 $(36.46 \%)$ babies who required neonatal intensive care admission.

No statistical association was seen with the mode of delivery. There were $7(7.29 \%)$ perinatal mortality of which 4 were stillbirths and 3 were early neonatal deaths ( 2 due to prematurity and 1 due to birth asphyxia). The mean birth weight of the first twin is $1.96 \pm 0.54 \mathrm{~kg}$. The mean birth weight of the second twin was $1.89 \pm 0.56 \mathrm{~kg}$ Table 5. Of the total babies $3(3.13 \%)$ were extremely low birth weight, $24(25 \%)$ were very low birth weight, $49(51.04 \%)$ were low birth weight and 20 (20.83\%) had normal weight.

Table 5: Birth weight.

\begin{tabular}{|lll|}
\hline Birth weight & Total & Percentage \\
\hline ELBW & 3 & 3.13 \\
\hline VLBW & 24 & 25 \\
\hline LBW & 49 & 51.04 \\
\hline Normal & 20 & 20.83 \\
\hline
\end{tabular}

\section{DISCUSSION}

Over the years with improved obstetrical and neonatal care, the incidence of maternal and perinatal mortality is in a decreasing trend. It is known that twin pregnancy is associated with a higher maternal and fetal risk. More women are undergoing ART due to subfertility following delayed marriage and lifestyle changes.

In India the incidence of twin is $1 \%$ of pregnancies and is the cause of $10 \%$ of perinatal mortality. ${ }^{13,14}$ In the present study the twinning rate is $20 / 1000$ deliveries which is high and comparable to African studies which reports a high incidence ranging from 20-40/1000 deliveries. ${ }^{15}$ This high rate could be due to our centre being the only tertiary hospital in the state with a good facility for high risk neonates. As seen that $54.1 \%$ of the cases were not booked and mostly referred.

Most of the women 24 (48\%) in the present study were in the age group 20-29 years with the mean age group $28 \pm 5.7$ years. Bassay and Dodd observed a similar mean age in their respective studies. ${ }^{16,17}$ In the present study a total of 26 (52\%) women had undergone LSCS. This data is similar to study by Lee $\mathrm{HC}, 53.4 \%$. There is an increasing trend of LSCS in twin pregnancy over the decade. ${ }^{18}$
In the present study the rate of LSCS in women $>35$ years is $62.5 \%$. In other studies, the rate of LSCS in women $>40$ is $59.1 \%$. We did not take a cut off age of 40 as the sample size is small. Present study multigravida twin was more $(70.83 \%)$. Akaba noticed a higher incidence of twinning in mothers with a parity of 2 as compared nulliparous mothers increased incidence of twin rates among women older than 35 years is well reported, resulting from physiologic endogenous ovarian hyperstimulation and higher use of techniques for assisted fertilization. ${ }^{15,19}$

Most of the women conceived spontaneously $36(75 \%)$ and $12(25 \%)$ conceived following ovulation induction including IVF. Among the women conceived following OI $1(8.3 \%)$ delivered vaginally and the rest $11(91.67 \%)$ had a LSCS ( $\mathrm{p}=0.0026)$ which is statistically significant. This result is similar to a study by Baxi A. ${ }^{20}$ Most women wanted a caesarean section maybe due to apprehension. Obstetricians lean toward cesarean delivery in twin pregnancy. ${ }^{11}$ Also Obstetricians anxiety and their concern while managing pregnancies in infertile women may increase the rate of cesarean section in this group of patients. Although studies have suggested that the outcomes were not improved by cesarean section. ${ }^{21}$

In the present study the most common indication for LSCS was fetal malpresentation which was similar to that of Yasmeen S. ${ }^{22}$ Fetal distress was the second most common indication for LSCS followed by elective LSCS done on maternal request $(10.42 \%)$. A similar finding in a study by Liu AL was seen in which the rate of LSCS on maternal request was $20 \% .^{23}$

It is seen that the most common complication was anemia $13(27.08 \%)$ and pregnancy induced hypertension 13 (27.08\%). Hypertension was reported in $46.8 \%$ of women by both Laskov. ${ }^{24}$ There was no statistical association between the complications and mode of delivery which was similar to the finding of Mathew $\mathrm{R}$ et al. ${ }^{25}$ Other complications were Preterm premature rupture of membrane 5 (10.42\%), antepartum hemorrhage 2 $(4.17 \%)$, hypothyroidism $4(8.33 \%)$.

Previous studies have revealed an increased risk of maternal postpartum complications, such as hemorrhage and endometritis, in twin pregnancies compared to singleton pregnancies. ${ }^{26}$ Women undergoing emergency cesarean deliveries were more likely to present infectious complications of any type (clinical, surgical wound and endometritis) where as we in our study did not find any statistical correlation between the postpartum complication and the mode of delivery.

$(58.33 \%)$ of the women had preterm labor, of which 11 $(39.29 \%)$ had vaginal delivery and $17(60.71 \%)$. This is similar to $60 \%$ of the twins delivered in the United States were preterm. ${ }^{15}$ Among the preterm babies $60.7 \%$ were delivered by LSCS, where as in a study conducted in Pakistan $94.3 \%$ of the preterm twin had a LSCS. ${ }^{27}$ 
Perinatal outcome in the form of Apgar score was studied and we found no statistical relation between the mode of delivery and the Apgar score at 5 minutes. Also, we found no association between the mode of delivery and perinatal morbidity in the form of babies requiring NICU admission. Our findings were similar to other studies in which the outcome of planned vaginal versus planned LSCS was carried out and no effect on the perinatal morbidity was seen between the two groups. ${ }^{23}$ Twin pregnancy is more likely to be characterized by LBW than singleton pregnancy mostly due to fetal growth restriction. There were 4 stillbirths in unbooked, referred patients and $3(3.1 \%)$ were early neonatal death.

\section{CONCLUSION}

As we know twin pregnancy is associated with a high risk in mother as well as foetus. There are an increased number of twins conceived after ovulation induction (ART). Various studies have been conducted to find the optimum mode of deliveries. In our studies we found an increase percentage of LSCS in twin pregnancies some of which were due to maternal request. Especially in women with precious pregnancy, conceived after treatment. Though there is no proven benefit of LSCS on the perinatal outcome yet there is a rise of LSCS rate in twin pregnancy (vertex-vertex). Thus, it is important to counsel the patient regarding the mode of delivery and the short term and long-term effects. Also, twin pregnancies once diagnosed must attend routine antenatal check-ups for early diagnosis and management of complications. Even if the pregnancy is a precious pregnancy, one must not incline towards caesarean delivery.

Funding: No funding sources Conflict of interest: None declared

Ethical approval: The study was approved by the Institutional Ethics Committee

\section{REFERENCES}

1. Fletcher GE, Zach T. Multiple Births. Medscape. 2015.

2. Cunningham FG, Leveno KJ, Bloom SL, Hauth JC, Rouse DJ. Williams Obstetrics. McGraw-Hill USA. $23^{\text {rd }}$ edition; 2010.

3. Mather JE, Pam VC. Obstetric outcome of twin pregnancies in Jos, Nigeria: a 16-month review in Jos University Hospital, Nigeria. Niger J Clin Pract. 2007;10(1):15-8.

4. Young BC, Wylie BJ. Effects of twin gestation on maternal morbidity. Semin Perinatol. 2012;36:162-8.

5. Tilahun T, Araya F, Tura G. Incidence and risk factors of twin pregnancy at Jimma University Specialized Hospital, Southwest Ethiopia. Epidemiol 2015;5:188.

6. Dutta DC. Text book of obstetrics including perinatology and contraception. $6^{\text {th }}$ ed. Calcutta: New Central Book Agency (P) Ltd; 2013.
7. Vendittelli F, Rivière $\mathrm{O}, \mathrm{CRENN}-\mathrm{HÉ} B E R T$ CA, Riethmuller D, SCHAAL JP, Dreyfus M. Is a planned cesarean necessary in twin pregnancies?. Acta obstetricia et gynecologica Scandinavica. 2011;90(10):1147-56.

8. Adler-Levy Y, Lunenfeld E, Levy A. Obstetric outcome of twin pregnancies conceived by in vitro fertilization and ovulation induction compared with those conceived spontaneously. Eur J Obstet Gynecol Reprod Biol. 2007;133:173-8.

9. Menacker F, Hamilton BE. Recent trends in cesarean delivery in the United States. NCHS Data Brief. 2010.(35):1-8.

10. Fox NS, Silverstein M, Bender S, Klauser CK, Saltzman DH, Rebarber A. Active second-stage management in twin pregnancies undergoing planned vaginal delivery in a US population. Obstet Gynecol. 2010;115(2)(1):229-33.

11. Schmitz T, Carnavalet Cde C, Azria E, Lopez E, Cabrol D, Goffinet F. Neonatal outcomes of twin pregnancy according to the planned mode of delivery. Obstet Gynecol. 2008;3(111):695-703.

12. Sullivan EA, Chapman MG, Wang YA, Adamson GD. Population-based study of cesarean section after in vitro fertilization in Australia. Birth. 2010;37:18491.

13. Murukesan L, Brahmanandan M. Fetal complications in twin pregnancies with special reference to chorionicity. Academic Med J India. 2015;3(1):13-7.

14. Nwankwo TO, Aniebue UU, Ezenkwele E, Nwafor MI. Pregnancy outcome and factors affecting vaginal delivery of twins at University of Nigeria Teaching Hospital Enugu. Niger J Clin Pract. 2013;16:490-5.

15. Akaba GO, Agida TE, Onafowokan O, Offiong RA, Adewole ND. Review of twin pregnancies in a tertiary hospital in Abuja, Nigeria. J Health Popul Nutr. 2013;31(2):272-7.

16. Bassey G, Inimgba NM. Fetomaternal outcome of twin gestation in Port Harcourt, South Nigeria. Niger J Med. 2014;23(4):282-7.

17. Dodd JM, Crowther CA, Haslam RR, Robinson JS. Elective birth at 37 weeks of gestation versus standard care for women with an uncomplicated twin pregnancy at term: the twins timing of birth at term randomised trial. BJOG. 2012;119(8):964-73.

18. Henry. Trends in cesarean delivery for twin births in the United States: 1995 to 2008. Obstet Gynecol. 2011;118(5):1095-101.

19. Ananth CV, Chauhan SP. Epidemiology of twinning in developed countries. Semin Perinatol. 2012;36:1561.

20. Baxi A, Kaushal M. Outcome of twin pregnancies conceived after assisted reproductive techniques. J Hum Reprod Sci. 2008;1(1):25-8.

21. Ganchimeg T, Morisaki N, Vogel JP, Cecatti JG, Barrett J, Jayaratne K, et al. Mode and timing of twin delivery and perinatal outcomes in low- and middleincome countries: a secondary analysis of the WHO Multi country Survey on Maternal and Newborn Health. BJOG. 2014;121(1):89-100. 
22. Rather SY. Studying pregnancy outcome in twin gestation in developing world. IOSRJDMS. 2014;13(5):2279-0853.

23. Liu AL, Yung WK, Yeung HN, Lai SF, Lam MT, Lai FK et al. Factors influencing the mode of delivery and associated pregnancy outcomes for twins: a retrospective cohort study in a public hospital. Hong Kong Med. 2012;18(2):99-107.

24. Laskov L, Michaan N, Cohen A, Tsafir Z, Maslovitz $\mathrm{S}$, Kupferminc M, et al. Outcome of twin pregnancy in women $\geq 45$ years old; a retrospective cohort study. J Matern Fetal Neonatal Med. 2013;26(7):669-72.

25. Mathew R, Wills V. Maternal determinants and fetal outcome of twin pregnancy: a five-year survey. Int $\mathrm{J}$
Reprod Contracept Obstet Gynecol. 2017;6(6):245965.

26. Stach SL, Zugaib M. Maternal postpartum complications according to delivery mode in twin pregnancies. Clinics (Sao Paulo). 2014;69(7):447-51.

27. Nihal Z. Preterm birth in twin pregnancies: Clinical outcomes and predictive parameters. Pak J Med Sci. 2016;32(4):922-6.

Cite this article as: Pyrbot JE, Agarwal M. Twin pregnancy-maternal and fetal complications its association with mode of delivery: a study in a tertiary center. Int J Reprod Contracept Obstet Gynecol 2017;6:5089-94. 